\title{
Countercurrent Gradient Chromatography: A Continuous Focusing Technique
}

\author{
Lisa L. Evans and Mark A. Burns* \\ Department of Chemical Engineering, University of Michigan, \\ Ann Arbor, Michigan 48109-2136
}

Received November 22, 1994/Accepted July 10, 1995

The continuous separation of proteins was performed in a countercurrent gradient chromatography (CGC) sys, tem. A magnetically stabilized fluidized bed (MSFB) was used to establish true countercurrent contact of a solid resin with a liquid buffer. Stable $\mathrm{pH}$ gradients were formed in the system in less than 10 min and remained stable throughout the course of the separation experiment $(>2 \mathrm{~h})$. The shape of the $\mathrm{pH}$ gradient, which ultimately controls the resolution and purity of the separation, can be controlled by making simple adjustments in the interstitial velocities of the liquid and solid phases. We have performed the separation of myoglobin and human serum albumin (HSA) using this device and achieved concentration factors of 1.75 for myoglobin and 1.2 for HSA. A mathematical model that has no adjustable parameters has been developed that predicts the focusing behavior and capabilities of the CGC system. Using the model, we have estimated the optimum phase velocities, particle diameters, and equilibrium parameters necessary for achieving high purity and high concentrations. (c) 1995 John Wiley \& Sons, Inc.

Key words: countercurrent gradient chromatography • protein separation - human serum albumin - chromatography

\section{INTRODUCTION}

Many different separation processes are required for the downstream recovery of fermentation products, such as therapeutic enzymes and monoclonal antibodies. Because these products typically require different purification treatments, a recovery process may call for a complicated multicomponent purification scheme (more than five steps), or a simple crude separation (two or three steps). Final product specifications may demand high product yield ( $>99 \%$ recovery), high concentration (increases of one to three orders of magnitude), or high purity $(>95 \%) .{ }^{10,33}$ Although no separation technique can meet all of these specifications, the achievement of more than one separation goal in a single unit is desirable.

Focusing is a separation method that accomplishes several of these goals at once. Solute focusing involves the separation and concentration of solutes based on a specific characteristic (net charge, density, size, hydrophobicity,

\footnotetext{
* To whom all correspondence should be addressed.
}

etc.) and uses the combination of a gradient and a force to resist the disruptive effects of diffusion and dispersion. In focusing, a solute will concentrate in a sharp, narrow zone at a discrete location in the separation system. By using the mechanism of focusing to separate solutes from multicomponent feeds, it is possible to achieve high concentration while resolving multiple peaks.

Presently, there exist several focusing techniques that can meet the demands of high concentration and high resolution. ${ }^{11}$ In isoelectric focusing (IEF), ${ }^{20,21,26}$ the most widely used focusing technique, amphoteric solutes are separated in a stable $\mathrm{pH}$ gradient on the basis of isoelectric point ( $\mathrm{pl}$ ). Although IEF has a high power requirement and requires the use of special chemicals such as carrier ampholytes or immobilines, IEF is well known for its ability to provide extremely high resolution and is widely used for high purity separations.

Several other focusing techniques have been developed to increase the potential impact of focusing. In one such technique, counteracting chromatographic electrophoresis (CACE),${ }^{14,16-18}$ solutes are focused in a gradient of matrix pore sizes and are separated on the basis of molecular weight. Like IEF, CACE requires the use of high-power electric fields to perform separations, but because the separation is performed chromatographically, the technique may scale more easily than IEF.

Of the existing focusing techniques, one of the easiest to scale is chromatofocusing (CF) ${ }^{27-29} \mathrm{CF}$ is a batch chromatographic focusing technique that is used to separate amphoteric solutes in a time-variant $\mathrm{pH}$ gradient. As the $\mathrm{pH}$ changes in a CF column, solutes are eluted from the column in order of their respective isoelectric points. CF has the advantage of scalability, no power requirement, and high resolution.

We have developed a chromatographic focusing technique based on the principle of chromatofocusing called countercurrent gradient chromatography (CGC). ${ }^{12}$ Using countercurrent contact, CGC separates amphoteric solutes on the basis of ionic charge in a stable (time-invariant) $\mathrm{pH}$ gradient. CGC is continuous, is easy to scale, and can concentrate and separate solutes from multicomponent feeds. Note that CGC is not restricted to separations in $\mathrm{pH}$ gradients; separations based on other solute characteristics (hydrophobicity, temperature, etc.) can also be performed. 
The mechanism and operation of a CGC system is shown in Figure 1. In the figure, a stable $\mathrm{pH}$ gradient is formed along the length of the column by the countercurrent contact of a low $\mathrm{pH}$ solids phase with a high $\mathrm{pH}$ liquid phase. ${ }^{11}$ Solutes entering the bottom of the column are negatively charged (high $\mathrm{pH}$ ) and are repelled by the negatively charged cation exchanger. The solutes are carried upward by the liquid phase until they reach their equilibrium positions (location near the isoelectric point of the solute). If a solute moves above this point, it becomes positively charged and adsorbs onto the cation exchange resin. Once adsorbed, the solute is carried down the column with the resin until it again reaches the vertical location where the $\mathrm{pH}=\mathrm{pl}$ and desorbs from the resin. This cyclic adsorption/ desorption mechanism caused by the combination of countercurrent flow and a stable $\mathrm{pH}$ gradient produces steady state focusing in the region of the solute's isoelectric point. Solutes with different $\mathrm{pl}$ values can be separated and concentrated at different locations in the column based on this focusing principle.

Performing separations in the CGC system has several advantages over current focusing techniques. CGC is a continuous chromatographic technique that is easy to scale and is capable of performing high capacity separations. The technique does not require the use of carrier ampholytes. Hence, separation of the products from the ampholytes is not required. In addition, CGC does not require a high power electric field to achieve focusing. Different types of $\mathrm{pH}$ gradients can be formed according to the desired sepa- ration; these gradients are easy to form and can be adjusted throughout the experiment by merely changing the liquid or solid flow rates.

The one major disadvantage of CGC is that countercurrent solid-liquid motion is necessary. Although there are many simulated countercurrent systems that can approximate this performance, ${ }^{1,5,8,9,23}$ we have chosen to use a magnetically stabilized fluidized bed (MSFB). The MSFB is a continuous flow system that provides true countercurrent contact between the adsorbent phase and the liquid phase. ${ }^{22}$ In the MSFB, magnetically susceptible solids (e.g., nickel particles) are stabilized in the presence of a low power $(10 \mathrm{~W} / \mathrm{L})$, uniform, vertically oriented magnetic field. The stabilized particles retain the fluidlike properties of a fluidized bed and can be drawn down through the column in plug-flow motion, thus achieving countercurrent contact. ${ }^{2}$ The magnetic field serves only to stabilize the particles and does not participate in the formation of the $\mathrm{pH}$ gradient or in the separation of solutes, and the field does not introduce any heat into the system. Dispersion and mass transfer properties of the MSFB are similar to those of packed bed systems. ${ }^{13}$ Solute separations in MSFBs offer the advantages of high separation efficiencies, large throughput rates, continuous feed injection, low pressure drop, direct fermentation broth processing, and ease of operation. $3,4,7,30,31$

Although the MSFB does provide the countercurrent contact necessary for proper operation of the CGC system, the requirement of a magnetically susceptible support is some-

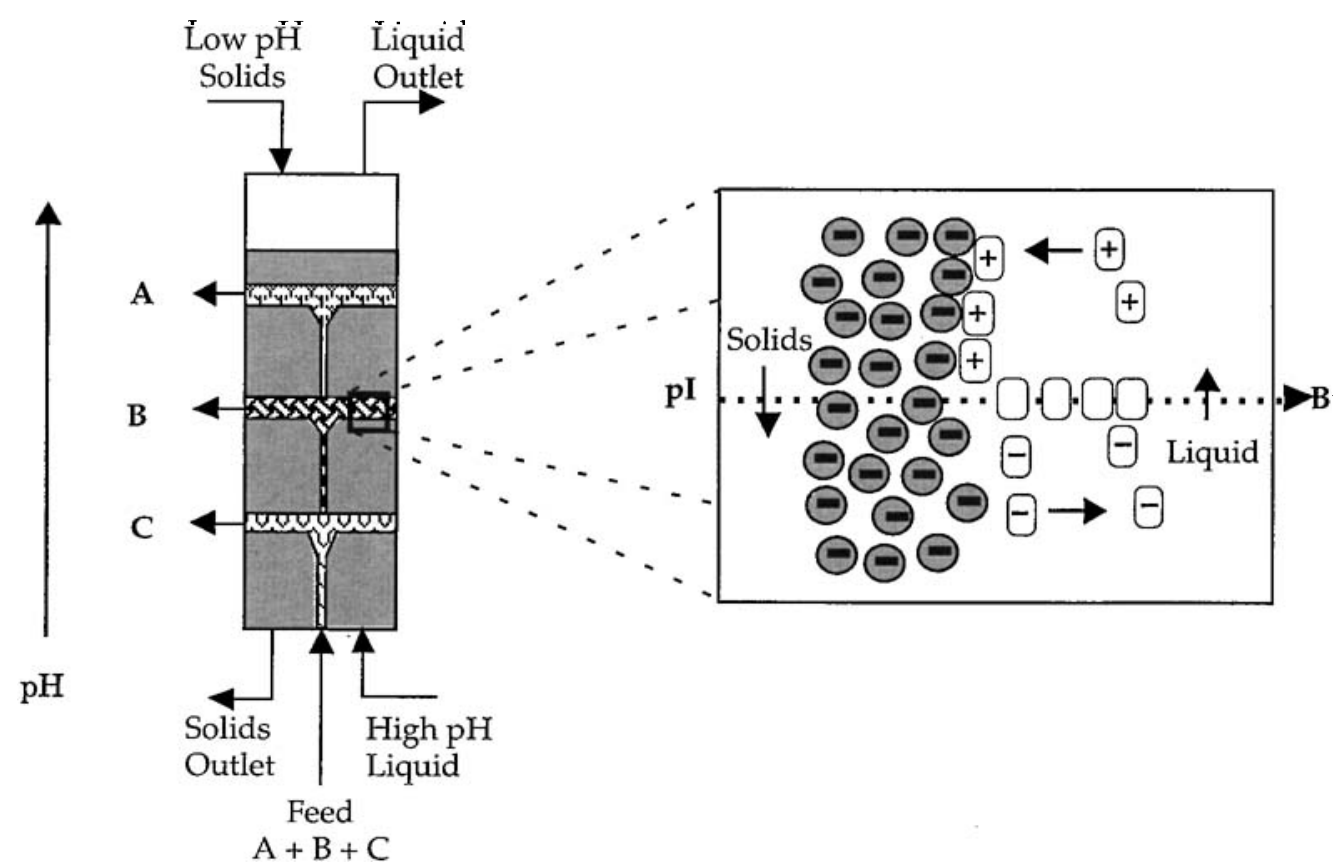

Figure 1. Separation of solutes A, B, and C in a CGC focusing system. Each solute focuses near its respective isoelectric point along the length of the column and can be withdrawn as a pure component. The mechanism of this focusing is shown in the insert. A solute is negatively charged at positions where $\mathrm{pH}>\mathrm{pI}$. In this region, the solute does not adsorb onto the negatively charged resin and is carried up the column. At $\mathrm{pH}<\mathrm{pI}$, the solute is positively charged. In this region, the solute adsorbs onto the negatively charged resin and is carried down the column. At $\mathrm{pH}=\mathrm{pI}$, the solute is neutrally charged and therefore focuses near that position. 
what restricting. While there is an abundance of commercially available nonmagnetic chromatographic supports designed specifically for the separation of biological molecules, magnetically susceptible versions are not always readily accessible.

A multisupport MSFB alleviates this problem by using inert magnetic particles to stabilize nonmagnetic separation resins. ${ }^{7}$ In a multisupport bed, magnetically susceptible particles and nonmagnetic particles are simultaneously introduced into the column in the presence of a low power magnetic field. The nonmagnetic particles are trapped by the magnetically susceptible particles and held in a magnetic matrix; the fraction of nonmagnetic particles in this matrix is set by adjusting the inlet velocity of the two solids phases into the column. The multisupport MSFB possesses all of the flow characteristics and mass transfer properties of a single support MSFB and has been used for continuous protein separations. ${ }^{6}$

In this article, we will describe the basic phenomena of CGC and discuss experimental and theoretical results that we have obtained. We use a multisupport MSFB system to perform the experimental separation and focusing of proteins. We use our mathematical model to predict the separations of those proteins and to optimize the experimental parameters.

\section{THEORETICAL MODEL}

In modeling the CGC system, we have assumed that there is no solids dispersion (i.e., plug flow motion of the solids). Burns and Graves ${ }^{2}$ have shown that solids dispersion is nonexistent in MSFB systems. We also assume that the solutions are dilute and that the solutes' adsorption isotherms are linear. This assumption is reasonable based on the experimental range of concentrations that are achieved in this system. However, this assumption must be modified if the model is extended to concentrated solutions. Intraparticle diffusion is neglected because the rate of radial transport of solute into the particle is several orders of magnitude smaller than the rate of convective transport. For this type of countercurrent adsorption system, the rate of adsorption and desorption is governed by the convective mass transfer; solutes adsorb near the surface and do not penetrate into the particles. Intraparticle diffusion has been neglected in similar models reported in the literature for countercurrent adsorption systems. ${ }^{24}$

With these simplifying assumptions, the overall differential mass balance equations for solute in the bulk fluid and particle phases are:

$$
\begin{aligned}
& \frac{\partial c}{\partial t}=-\frac{v_{L}}{\epsilon} \frac{\partial c}{\partial z}+E_{L} \frac{\partial^{2} c}{\partial z^{2}}-\frac{1-\epsilon}{\epsilon} k a\left(c-c^{*}\right) \\
& \frac{\partial q}{\partial t}=\frac{v_{S}}{1-\epsilon} \frac{\partial q}{\partial z}+\frac{1-\epsilon}{\epsilon} k a\left(c-c^{*}\right)
\end{aligned}
$$

where $v_{L}$ and $v_{S}$ are the liquid and solids superficial veloc- ities, $c$ and $q$ are the solute concentrations in the liquid (per liquid volume) and solids (per solid volume) phases $k$ is the mass transfer coefficient, $a$ is the surface area per volume for the solids, $\epsilon$ is the void fraction, $z$ is the position in the column, $t$ is time, and $E_{L}$ is the liquid dispersion coefficient. The mass transfer coefficient is determined from the correlation for packed beds

$$
k=1.17 v^{0}\left(\frac{d v^{0}}{v}\right)^{-0.42}\left(\frac{v}{D}\right)^{-0.67}
$$

where $v^{0}$ is the superficial velocity, $d$ is the particle diameter, $D$ is the solute diffusion coefficient, and $v$ is the kinematic viscosity.

Eqs. (1) and (2) are coupled through an equilibrium isotherm. When the concentration of solute in the mobile phase is low, the asumption of a linear adsorption isotherm is valid where $K(z)$ is the equilibrium constant, i.e.,

$$
q=K(z) c^{*}
$$

Note that the liquid-solid equilibrium is a function of $\mathrm{pH}$ and, therefore, distance. Also, for mixed-bed systems, Eq. (1)-(4) must be modified to account for a fraction of nonmagnetic support in the bed. This modification is accomplished by multiplying $K(z)$ (reduced capacity of the column) and $a$ (reduced area for transport) by the volume fraction of nonmagnetic support.

The variables are made dimensionless with the following parameters:

$$
\zeta=\frac{z}{L}, \quad \Psi=\frac{c}{c_{o}}, \quad \Phi=\frac{q}{c_{o}} \frac{(1-\epsilon)}{\epsilon}, \quad \tau=\frac{\nu_{L} t}{\epsilon L}
$$

where $L$ is the bed height, $c_{o}$ is the initial feed concentration in the liquid phase, $\Psi$ is the dimensionless liquid-phase solute concentration of solute, $\zeta$ is the dimensionless length of the column, $\Phi$ is the dimensionless solid phase concentration, and $\tau$ is the dimensionless time.

Substituting the above dimensionless variables and assuming steady state, we arrive at the following dimensionless equations:

$$
\begin{gathered}
-\frac{d \Psi}{d \zeta}+\frac{1}{P e_{L}} \frac{d^{2} \Psi}{d \zeta^{2}}-S t\left(\Psi-\frac{\Phi}{\mathscr{K}(\zeta)}\right)=0 \\
\frac{d \Phi}{d \zeta}+\sigma S t\left(\Psi-\frac{\Phi}{\mathscr{K}(\zeta)}\right)=0 \\
\Phi_{i}=\mathscr{K}(\zeta) \Psi_{i}^{*}
\end{gathered}
$$

where the dimensionless parameters are defined as:

$$
\begin{gathered}
\sigma=\frac{(1-\epsilon) v_{L}}{\epsilon v_{S}}=\frac{\text { interstitial liquid velocity }}{\text { interstitial solids velocity }} \\
P e_{L}=\frac{v_{L} L}{\epsilon E}=\frac{\text { convective rate }}{\text { dispersive rate }}
\end{gathered}
$$




$$
\begin{aligned}
& \mathscr{K}(\zeta)=K(\zeta) \frac{(1-\epsilon)}{\epsilon}=\frac{\text { mass in solids }}{\text { mass in liquid }} \\
& S t=\frac{k a(1-\epsilon) L}{v_{L}}=\frac{\text { mass transfer rate }}{\text { convective rate }}
\end{aligned}
$$

The model also includes the effect of product withdrawal from ports placed along the length of the column. For product withdrawal, the term $\chi \gamma_{\zeta} \Psi_{\zeta}$ is subtracted from Eq. (5) where $\chi$ is the fraction of liquid from the port and $\gamma$ is the liquid ratio $\frac{v_{o}}{v_{L_{\zeta}}}$.

The boundary conditions below state that the feed enters at the bottom of the column in the liquid phase, and pure solids (no solute) enter at the top of the column:

$$
\begin{array}{rlrl}
\text { at } \zeta=0, & & \Psi=1 \\
\text { at } \zeta=1, & & \Phi=0 \\
\text { at } \zeta=1, & \frac{d \Psi}{d \zeta}=0
\end{array}
$$

For the $\mathrm{pH}$ gradient, the boundary conditions are:

$$
\begin{array}{ll}
\text { at } \zeta=0, & \Psi=1 \\
\text { at } \zeta=1, & \Phi=\frac{q_{o}}{c_{o}} \\
\text { at } \zeta=1, & \frac{d \Psi}{d \zeta}=0
\end{array}
$$

Note that, in the case of focusing, $\mathscr{K}(\zeta)$ is a function of $\mathrm{pH}$ and can be approximated by a hyperbolic tangent. For modeling purposes, we use the following expression for $\mathscr{K}(\zeta)$ :

$$
\mathscr{K}(\zeta)=\frac{\mathscr{K}_{\max }\left(1+\tanh \left(\beta\left(\mathrm{pH}_{\mathrm{I}}-\mathrm{pH}(\zeta)\right)\right)\right)}{2}
$$

where $\mathscr{T}_{\max }$ is the maximum equilibrium coefficient for adsorption, $\beta$ is a scale factor, $\mathrm{pH}_{\mathrm{I}}$ is inflection point of the equilibrium curve, and $\mathrm{pH}(\zeta)$ represents the positiondependent $\mathrm{pH}$ gradient in the column. For qualitative $\mathrm{pH}$ gradient prediction, we have assumed no buffering (i.e., no hydrogen ion adsorption/desorption). For this case, the model will predict the simple mixing of two countercurrent streams. The equilibrium constant is, therefore, a partition coefficient and is assumed to be equal to 1 .

Eqs. (5) and (6) were combined with Eqs. (7) and (12) and solved using finite difference methods. ${ }^{19}$ The equations were used to predict the concentration profiles of the solute as a function of position in the column. We have used this model to study the effects of the specific parameters on the resulting concentration profiles and to determine the optimum conditions for obtaining high resolution separations. Because all parameters in the model are determined independently, we have also used the model for a priori predictions of our experimental focusing results. Note that, for the experimental runs with sideport withdrawal, the model was applied to each section of the column and the liquid velocity was adjusted accordingly.

\section{MATERIALS}

Nickel particles ( 100 to $150 \mu \mathrm{m}$ in diameter) were purchased from Aesar. Amberlite IRC-50 (100 and $170 \mu \mathrm{m}$ in diameter) resin was donated by Rohm \& Haas. Myoglobin from horse skeletal muscle, chicken egg white lysozyme, human serum albumin (HSA), and ovalbumin were purchased from the Sigma Chemical Company. Specific characteristics of these proteins are shown in Table 1. Buffers including Tris(hydroxymethyl)-aminomethane (Tris buffer) and sodium acetate, were purchased from Sigma Chemical Company. Water was distilled using a Bronsted glass still and deionized in a Nanopure II deionizer. All other chemicals were purchased from commercially available sources.

\section{METHODS}

\section{Column Construction and Operation}

A 2-cm i.d. Plexiglass column was constructed with a rubber septum along its side (see Fig. 2). The column has a diameter of $2.54 \mathrm{~cm}$ and an adjustable length ranging from 10 to $100 \mathrm{~cm}$. Hypodermic needles $\left(27 \mathrm{G}^{1 / 2^{\prime}}\right)$ are inserted at different vertical locations along the septum for sample withdrawal. A $0.2-\mathrm{cm}$-thick polyethylene liquid distributor with pore sizes of 25 to $40 \mu \mathrm{m}$ is placed at the bottom of the column, and a $0.5-\mathrm{cm}$-diameter tube is inserted into the center of the distributor for solids withdrawal.

The solids are added to the column by pumping liquid buffer into a 5 -cm-diameter $\times 50$-cm-long glass reservoir with a $0.3-\mathrm{cm}$ drawn tip at the bottom and the solids flow rate controlled by the flow of buffer to the reservoir. Solids are removed from the column at a constant flow rate by placing the solids withdrawal tube into a sealed vacuum Erlenmeyer flask filled with desorbing buffer. When liquid is pumped out of the flask through the side arm, solids are

\begin{tabular}{|c|c|c|c|}
\hline Protein & $\begin{array}{c}\text { Diffusion } \\
\text { coefficient }^{\mathrm{a}} \\
\left(D \times 10^{-7}\right)\end{array}$ & $\mathrm{MW}^{\mathbf{a}}$ & pI \\
\hline Myoglobin & 11.3 & 17,000 & $6.8^{\mathrm{b}}$ \\
\hline Human serum albumin (HSA) & 5.7 & 65,000 & $4.9^{\mathrm{b}}$ \\
\hline Lysozyme & 11.8 & 14,400 & $11.0^{\mathrm{c}}$ \\
\hline Ovalbumin & 5.7 & 45,000 & $4.7^{\mathrm{b}}$ \\
\hline
\end{tabular}
drawn down through the column at a steady rate. Note that, to keep the linear velocity of liquid in the column constant, the liquid feed to the column is increased by the same amount as is being withdrawn from the solids withdrawal tube.

Fluid samples are removed from the bottom of the column through an opening in the solids withdrawal tube, and

Table I. Physical characteristics of proteins.

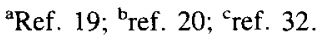




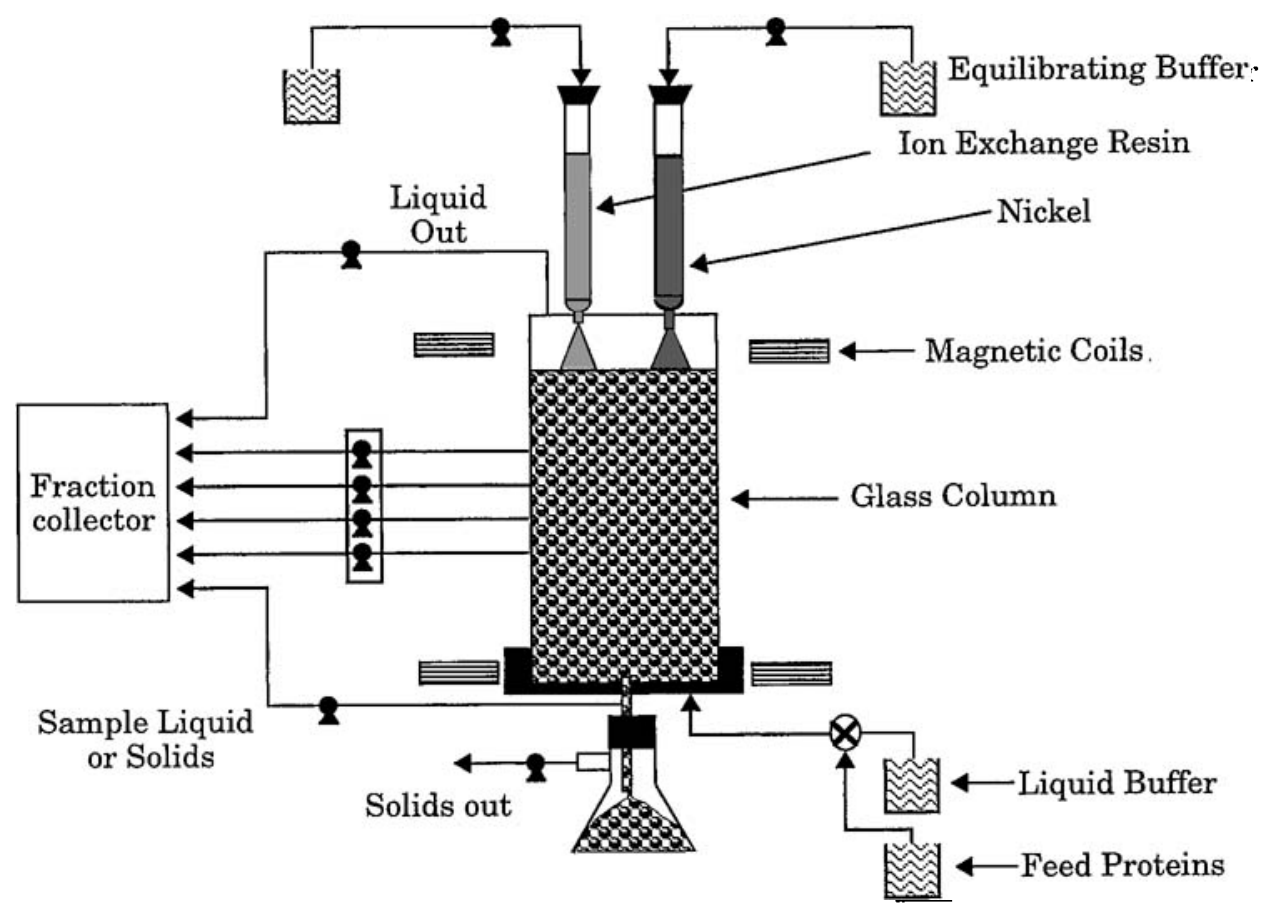

Figure 2. Experimental set-up. Nickel particles and ion exchange resins are added at the top of the column using the solids reservoirs. The solids are stabilized in the column using magnetic coils. The liquid buffer and protein feeds are introduced at the bottom and removed at the top of the column. These samples along with samples withdrawn along the side of the column through a rubber septum are sent to a spectrophotometer for analysis.

samples along the length of the column are removed through the needles and placed in the rubber septum. The fluidizing medium is introduced through a port below the liquid distributor and liquid overflow is removed at the top and collected for analysis. Magnetic coils (modified Helmholtz coils, $13.5 \mathrm{~cm}$ in diameter $\times 2.5 \mathrm{~cm}$ thickness, with centers spaced $9 \mathrm{~cm}$ apart) that are needed for the stabilization of the magnetic particles are constructed to produce magnetic fields as high as 150 Gauss.

\section{Support Preparation and Regeneration}

Fresh ion exchange support is washed in a chromatography column with a $0.1 \mathrm{M} \mathrm{NaOH}$ solution until the $\mathrm{pH}$ of the

Table II. Typical run conditions.

\begin{tabular}{ll}
\hline \multicolumn{1}{c}{ Parameters } & \multicolumn{1}{c}{$\begin{array}{c}\text { Experimental } \\
\text { range for testing }\end{array}$} \\
\hline Liquid flow rate & $3-30 \mathrm{~mL} / \mathrm{min}$ \\
Solids flow rate & $1-15 \mathrm{~mL} / \mathrm{min}$ \\
Liquid buffer & Tris buffer, $\mathrm{pH} 10.0$, \\
& $0.05-0.2 \mathrm{M}$ \\
Solids equilibration buffer & Sodium acetate buffer, $\mathrm{pH} 4.0$, \\
& $0.05-0.2 \mathrm{M}$ \\
Magnetic field & $50-80 \mathrm{Gauss}$ \\
Bed height & $16 \mathrm{~cm}$ \\
Bed ratio & $35 \% / 65 \%$ resin to nickel \\
Initial protein concentration & $0.1 \mathrm{mg} / \mathrm{mL}$ \\
\hline
\end{tabular}

supernatant approaches 10 and the absorbance of the supernatant at 280 and $410 \mathrm{~nm}$ is less than 0.002 . The solids are then rinsed with deionized water. Next, a solution of $0.1 \mathrm{M}$ $\mathrm{HCl}$ is passed through the column until the supernatant approaches a $\mathrm{pH}$ of 5 , and the solids are then equilibrated in $0.1 M$ sodium acetate buffer to a $\mathrm{pH}$ of 4.5 . Between experiments, the solids are washed with $0.1 M$ Tris solution $(\mathrm{pH} \mathrm{10)}$ and then the above procedure is repeated. For the nickel particles, the $150-\mu \mathrm{m}$ particles are washed with 1.0

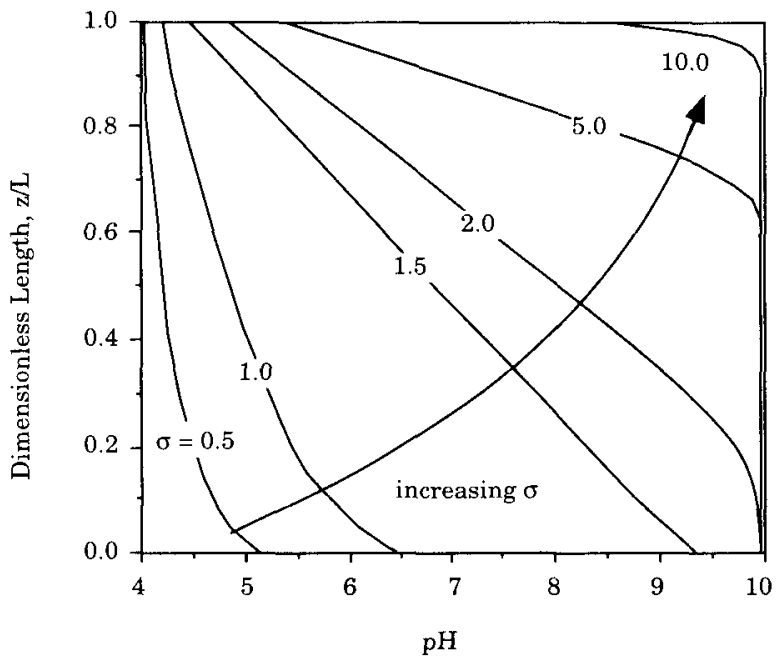

Figure 3. Model $\mathrm{pH}$ gradient. The mathematical model predicts that the $\mathrm{pH}$ gradient can be adjusted by varying the ratio of liquid to solids velocity $(\sigma)$. 


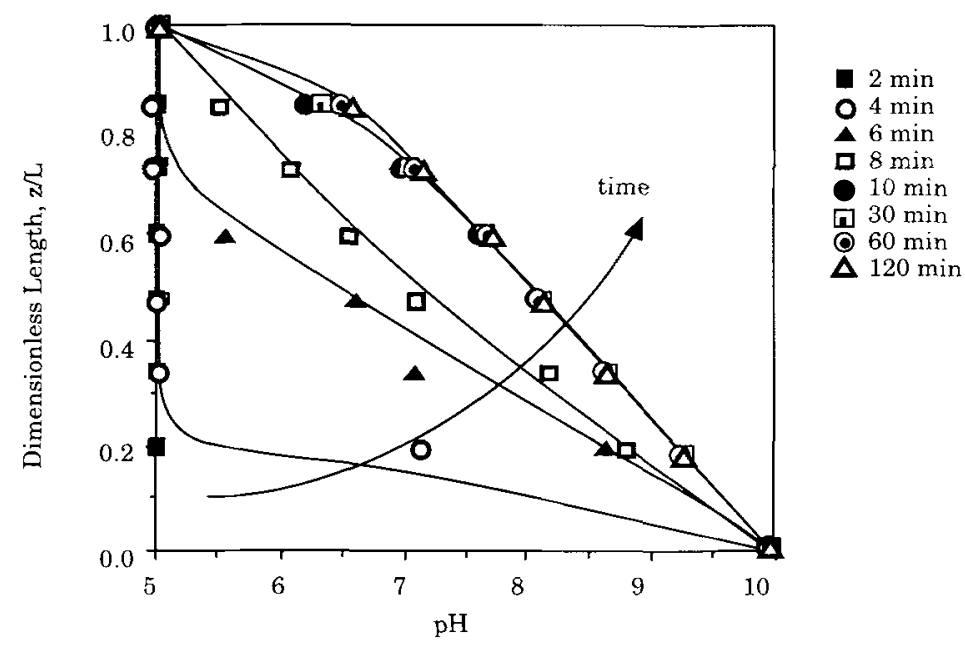

Figure 4. Formation of a stable $\mathrm{pH}$ gradient. IRC-50 ion exchange solids and nickel particles equilibrated to $\mathrm{pH} 5$ in sodium acetate buffer are introduced at the top of the column. Tris buffer adjusted to $\mathrm{pH} 10$ is introduced at the bottom of the column. The approach to steady state is shown for a $\sigma$ value of 3.5 . The gradient becomes stable in $10 \mathrm{~min}$ and remains stable for $-2 \mathrm{~h}$.

$M \mathrm{KCl}$ and then deionized water for 30-min intervals until the supernatant becomes clear (the absorbance at $610 \mathrm{~nm}$ is monitored). The nickel is then equilibrated with $0.1 \mathrm{M}$ sodium acetate buffer to a $\mathrm{pH}$ of 4.5 .

\section{Adsorption Isotherms}

After preparation as described above, equal volumes of the resin particles are equilibrated to different $\mathrm{pH}$ values (i.e., $4.5,5,6,7,8,9,10$ ) with $0.1 M$ Tris buffer. Three mil- liliters of protein solution ( $\mathrm{pH} 4.5$ ) are added to $1.0 \mathrm{~mL}$ of resin $(\mathrm{pH} \mathrm{4.5)}$ in a $13 \times 100 \mathrm{~mm}$ test tube and mixed using a Fisher Scientific Hematology/Chemistry mixer. The amount of protein adsorbed after 1, 2, and 3 days is measured using a Hewlett Packard Diode Array Spectrophotometer (280 $\mathrm{nm}$ and $410 \mathrm{~nm}$ [myoglobin]) to confirm that equilibrium was reached (point at which the concentration of protein in the liquid remains constant). All experiments are carried out at room temperature. The final $\mathrm{pH}$ values of each solution are measured when equilibrium is reached.

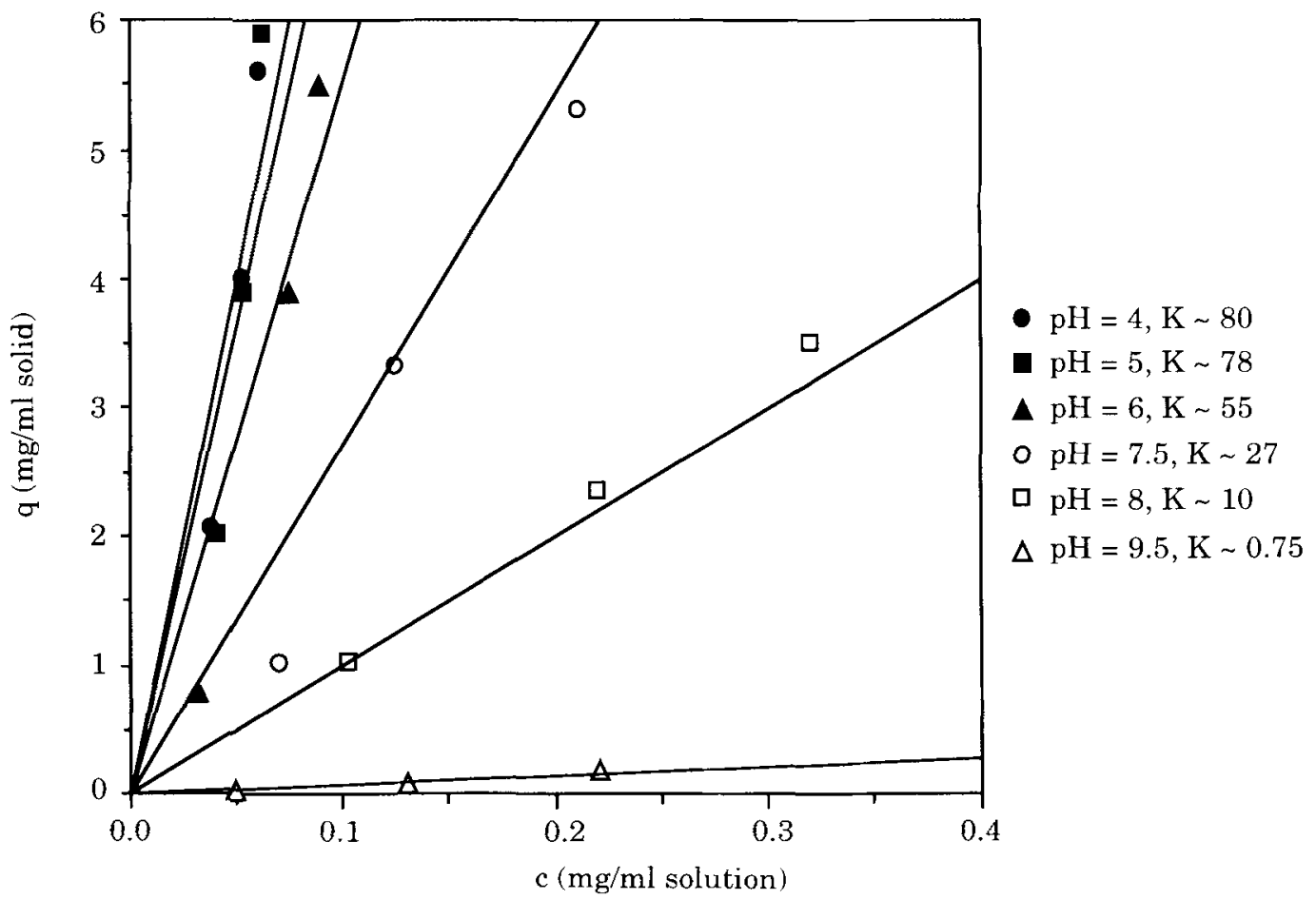

Figure 5. Equilibrium curves for myoglobin on IRC-50 $(-\mathrm{COOH})$ resin as a function of $\mathrm{pH}$. The equilibrium constant, $K$, decreases as a function of $\mathrm{pH}$. 


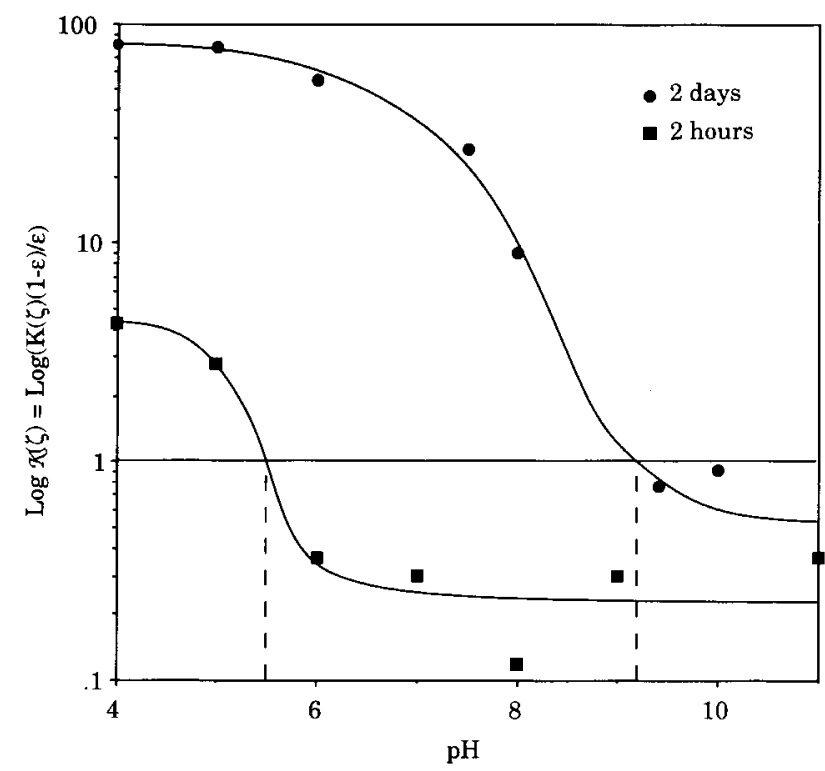

Figure 6. Kshift profiles for myoglobin. Equilibrium data obtained after $2 \mathrm{~h}$ were significantly different than those obtained after 2 days. Using the 2-h data in the model gave an underprediction of the focusing location in the column.

\section{Analysis of Protein Mixtures (Myoglobin + One Protein)}

The solutions are analyzed using a spectrophotometer and measuring the absorbance at $280 \mathrm{~nm}$ for total protein concentration and at $410 \mathrm{~nm}$ for myoglobin concentration. The corresponding absorbance reading for myoglobin at $280 \mathrm{~nm}$ is then determined. The concentration of the second protein is determined from the difference.

\section{Typical Focusing Experiment}

Initially, the column is filled with the fluidizing medium (sodium acetate buffer adjusted to $\mathrm{pH} 4.5$ ). With the fluidizing buffer flowing and the magnetic field set at 80 Gauss, nickel and resin particles (equilibrated to $\mathrm{pH} 4.5$ ) are introduced at the top of the column at a volume ratio of $65 / 35$ (nickel/resin). When the level of solids reaches $16 \mathrm{~cm}$, the solids withdrawal pump is turned to maintain a constant bed height of $16 \mathrm{~cm}$. The fluidizing medium is switched to Tris buffer $(\mathrm{pH} \mathrm{10})$ and the $\mathrm{pH}$ of the column is monitored at different locations. After a steady state $\mathrm{pH}$ profile is obtained (approximately $15 \mathrm{~min}$ ), the fluidizing medium is switched to a protein feed solution of $0.1 \mathrm{mg} / \mathrm{mL}$. The experimental conditions were varied as indicated in Table II.

\section{RESULTS AND DISCUSSION}

We have used a multisupport MSFB to form stable $\mathrm{pH}$ gradients and to separate proteins in these gradients. The mixed bed consists of $35 \%$ ion exchange resin and $65 \%$ nickel particles. The ratio of nonmagnetic to magnetic particles is controlled by adjusting the ratio of the solids flow rates from the two solids reservoirs. Thus, as long as the MSFB is stably fluidized, different ratios of solids can be used in the system. Our mathematical model accurately predicts our experimental results and can be used to optimize solute focusing in CGC.

\section{Model Predictions and Experimental Verification}

We have used the model to predict the shape of the $\mathrm{pH}$ gradient as a function of the ratio of interstitial velocities of

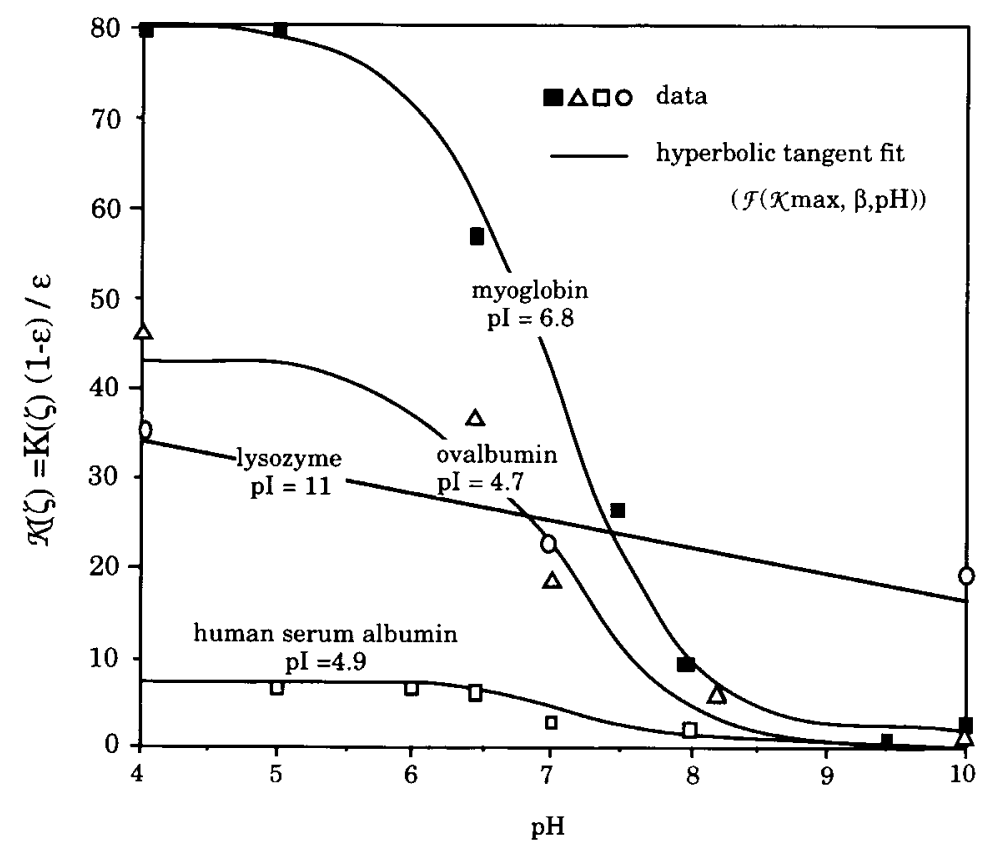

Figure 7. Kshifts for several proteins. Equilibrium data was determined experimentally for different proteins on the cation exchanger IRC-50 and fit to a hyperbolic tangent function. 


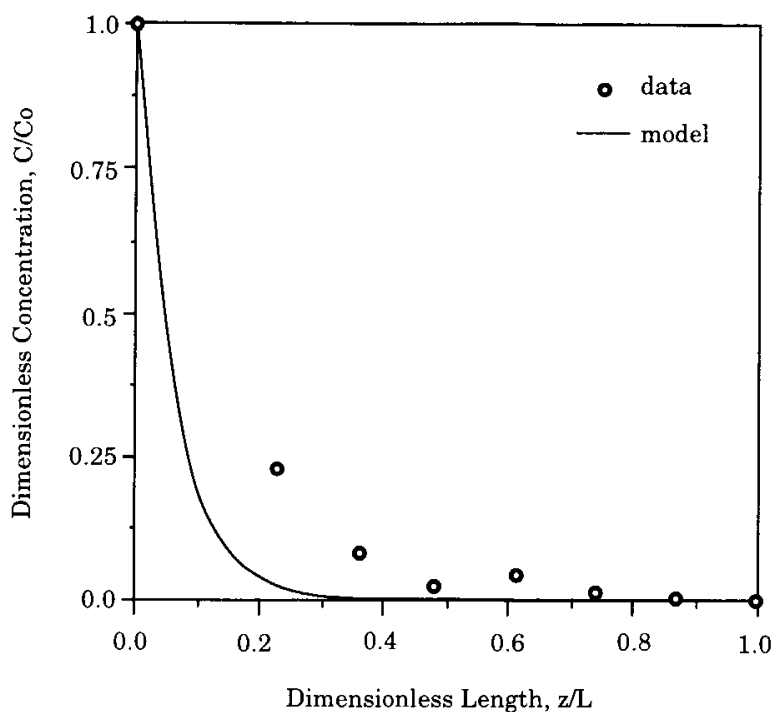

Figure 8. Straight adsorption of lysozyme. A $0.05 \mathrm{mg} / \mathrm{mL}$ feed solution of lysozyme adjusted to $\mathrm{pH} 4$ in sodium acetate buffer is introduced at the bottom of the column that has been equilibrated at $\mathrm{pH} 4$. Essentially, all of the lysozyme is continuously withdrawn from the bottom of the column. The model parameters are $\sigma=2, S t=2, P e_{L}=103$, and $\mathscr{K}$ function shown in Figure 7.

the liquid and solids phase $(\sigma)$. Figure 3 illustrates the $\mathrm{pH}$ gradients predicted by the model for a range of $\sigma$ values. Because the gradient is formed by the continuous exchange of $\mathrm{H}^{+}$ions along the length of the column, adjustments in the fluid flow rates can be used to control the gradient. The model shows that, as $\sigma$ is increased from 0.1 to $>5$, the shape of the $\mathrm{pH}$ profile in the column changes from a shallow linear gradient to a steep constant $\mathrm{pH}$ profile. These model results suggest that different gradient profiles can be formed, and that precise control of the gradient shape can be exercised by simple adjustments in $\sigma$.

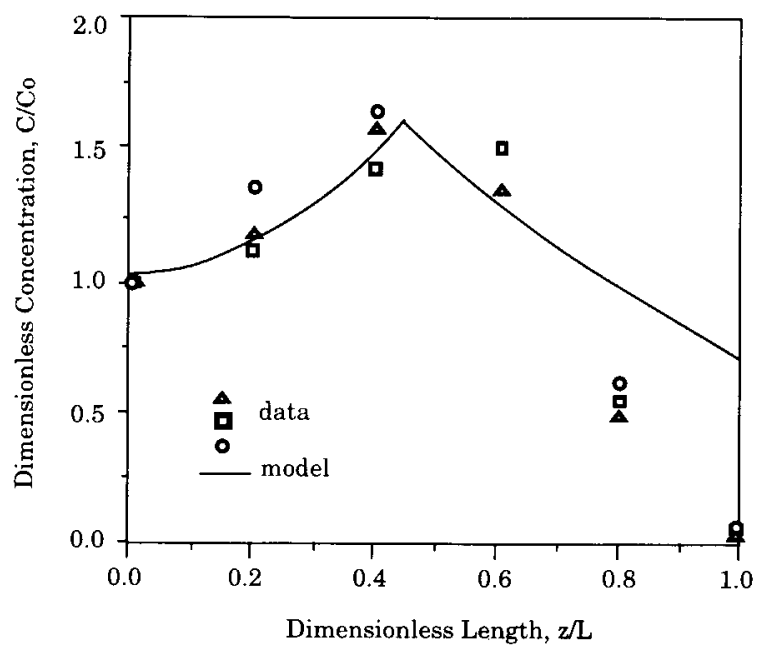

Figure 9. Single component focusing of myoglobin. A $0.2 \mathrm{mg} / \mathrm{mL}$ feed solution of myoglobin Tris buffer is introduced at the bottom of the column. A concentration factor of 1.7 times is achieved in the system, a value that is predicted by the mathematical model. The model parameter values are $S t=2, P e_{L}=105$, and $\sigma=2 ; \mathscr{K}$ is shown in Figure 7 .

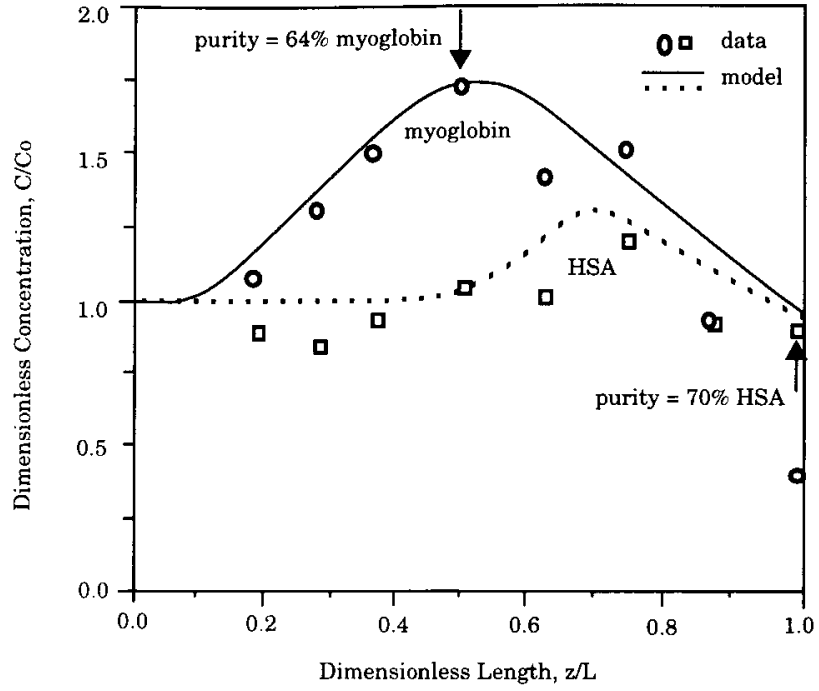

Figure 10. Separation of myoglobin and human serum albumin. At position 0.5 , a sample that was $64 \%$ myoglobin (1.75 times concentrated) was obtained. At position 0.75 , a sample 1.2 times concentrated of HSA was obtained. With $S t=2, P e_{L}=103, \sigma=2$, and the $\mathscr{K}$ values from Figure 7 , the model predictions of this separation agreed very well with the experimental results.

To verify the qualitative model results, we have formed experimental $\mathrm{pH}$ gradients in our CGC system. In general, we were able to duplicate the variety of $\mathrm{pH}$ profiles shown in Figure 3; Figure 4 shows an example of one such profile. The solids were adjusted to $\mathrm{pH} 5$, the liquid buffer was adjusted to $\mathrm{pH} 10$, and $\sigma$ was set at a value of 2 . Note that, for this $\sigma$ value, a stable, relatively linear $\mathrm{pH}$ gradient is formed in less than $10 \mathrm{~min}$ and remains stable throughout

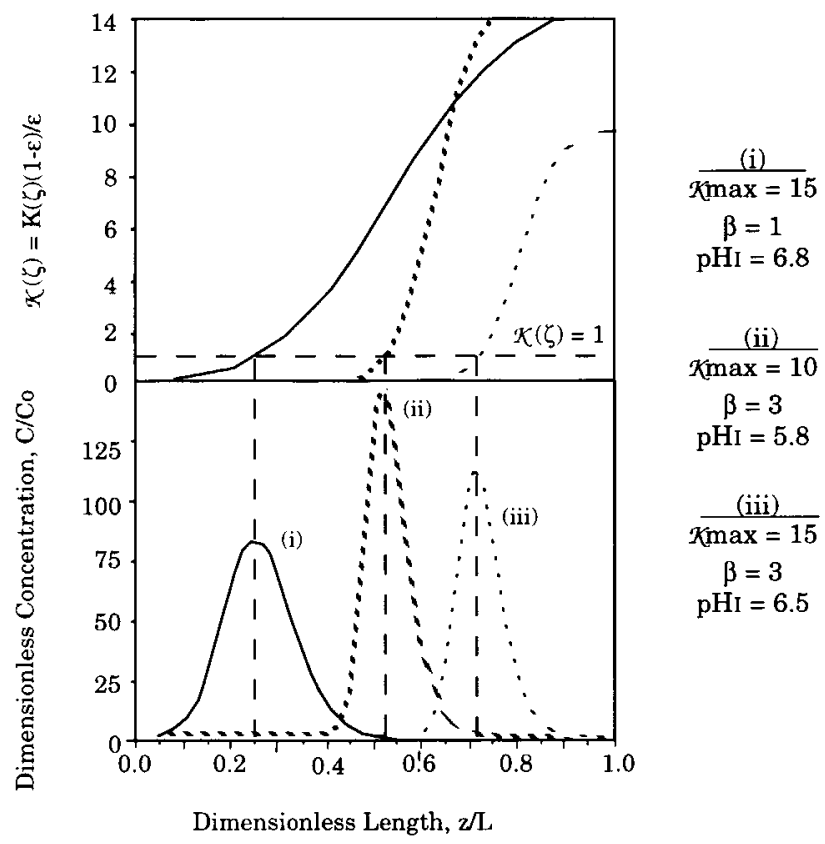

Figure 11. Effect of $\mathscr{K}$ shift on location of peak maximum. A peak will focus at the position where $\mathscr{K}=1$. The model values for these solutes are $\sigma=1, S t=50$, and $P e_{L}=105$. 


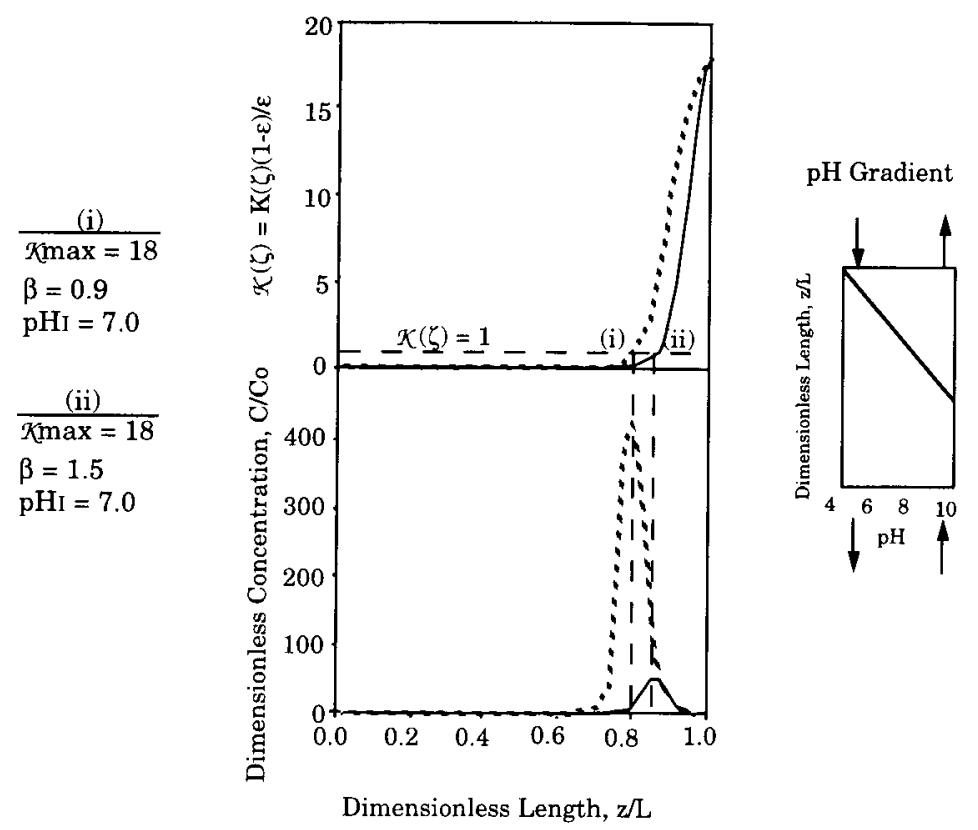

Figure 12. Effect of $\mathrm{pH}$ gradient on peak location. With this steep gradient, the solute peaks are severely overlapped. The model values for these solutes are $\sigma=3$, $S t=200$, and $P e_{L}=103$.

the course of the experiment (approximately $2 \mathrm{~h}$ ). Moreover, as long as sufficient material is available (solids and liquid buffer), the gradient would remain stable indefinitely.

The stable $\mathrm{pH}$ gradient controls the partitioning of the solute between the solid and liquid phases and allows focusing to occur. This partitioning is represented by the equilibrium constant, $K$, and varies depending on the $\mathrm{pH}$ in the column (greater than 1 at low $\mathrm{pH}$ to a near zero value at high $\mathrm{pH}$ ). Figure 5 shows the experimentally determined equilibrium curves for myoglobin on IRC-50 as a function of $\mathrm{pH}$. To obtain this relationship, we measured the isotherms at both short (measured isotherms after $20 \mathrm{~min}$ to $2 \mathrm{~h}$ ) and long (measured isotherms for 2 to 3 days) times. Figure 6 shows these isotherms for myoglobin. We determined that while the proteins remained in the column for $<2 \mathrm{~h}$, using

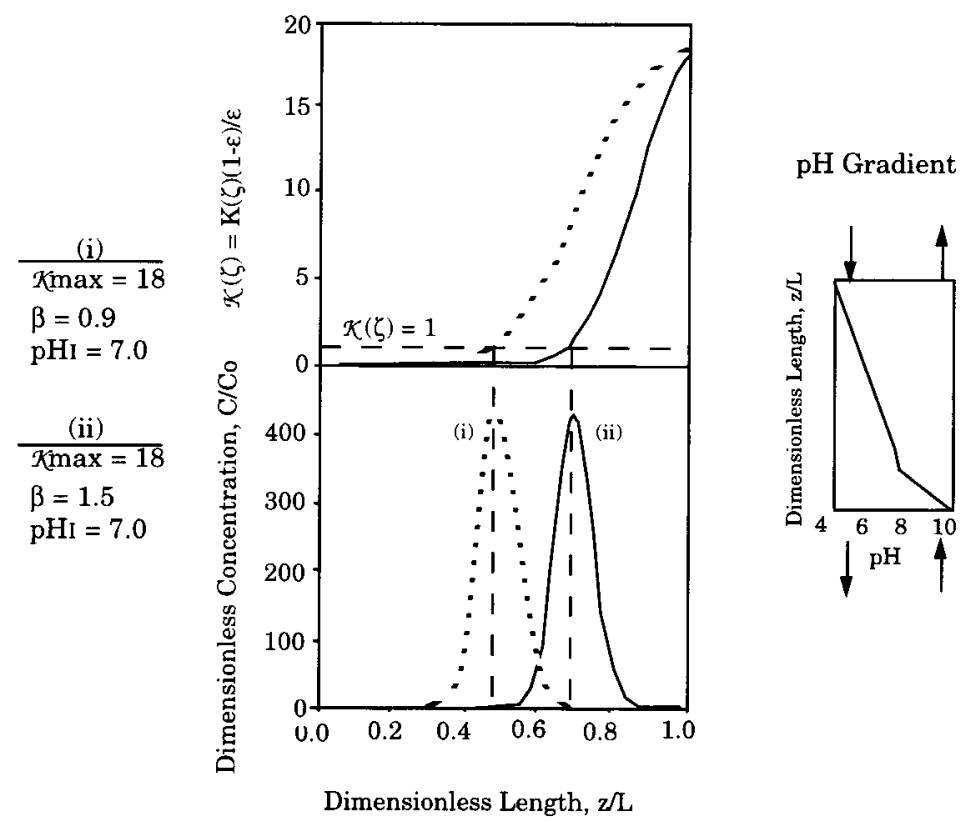

Figure 13. Effect of $\mathrm{pH}$ gradient on peak location. The hypothetical solutes are identical to those used to generate Figure 12 . The value of $\sigma$ is changed to 1.9 to achieve a new $\mathrm{pH}$ gradient. 


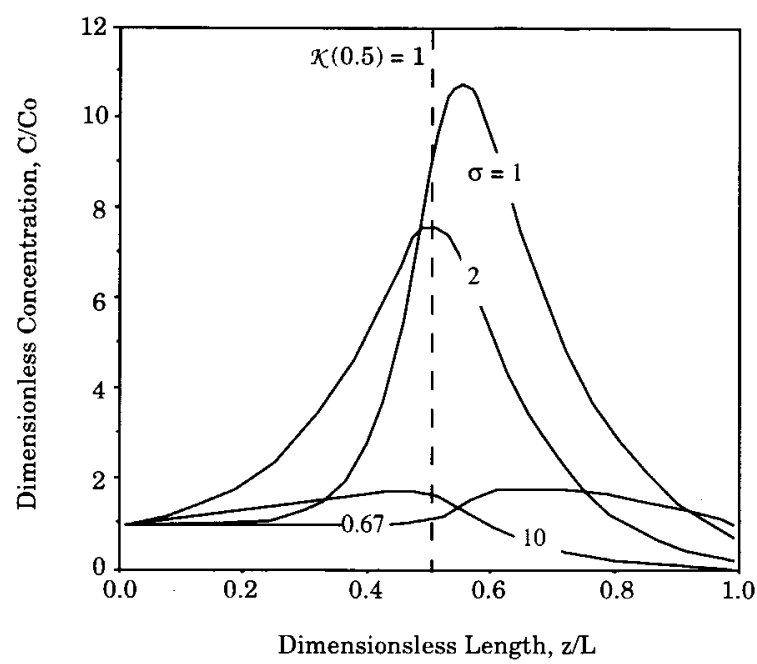

Figure 14. Effect of $\sigma$ on peak location. When $\sigma=1$, a peak will focus where $\mathscr{K} \sim 1$. When $\sigma>1$, the peak will focus above that position and when $\sigma<1$, a peak will focus below that position. At extreme values of $\sigma$, column end effects cause peak loss out of the ends of the column. The model parameters values are $S t=10, P e_{L}=105, \mathscr{K}_{\max }=20, \beta=2$, and $\mathrm{pH}_{1}=7$.

the dynamic isotherms gave an underprediction of focusing in CGC. However, the static isotherms gave relatively good predictions of the experimental results. Figure 7 shows the static equilibrium profiles for myoglobin and other model proteins on IRC-50, a weak acid cation exchanger.

We refer to this shift in the equilibrium constant as the $\mathscr{K}$-shift. The $\mathscr{K}$-shift determines whether or not a solute can be focused in $\mathrm{CGC}$ for a given $\mathrm{pH}$ gradient. At $\mathrm{pH}<$ pI, a protein will be positively charged, and will adsorb onto a cation exchanger; in this case, $\mathscr{K}$ will be greater than 1. On the other hand, at $\mathrm{pH}>\mathrm{pI}$, the solute will be negatively charged and $\mathscr{K}$ will approach zero. The reverse case is true for an anion exchanger. Also, because $\mathscr{K}$ is related to the equilibrium constant of the adsorption isotherm, different $\mathscr{K}$ values exist for different protein/exchanger systems. The $\mathscr{K}$-shift can usually be represented by a hyperbolic tangent function [Eq. (12)]. Note that for the $\mathscr{K}$-shifts shown in Figure 7 , the shifts occur for all proteins between the $\mathrm{pH}$ values of 6 and 9 . One of the characteristics of a weak acid or base resin is that there exists a gradual change in its exchange capacity as a function of $\mathrm{pH} .{ }^{25}$ Thus, the gradual change in the $\mathscr{K}$-shift that occurs within the 6 to $9 \mathrm{pH}$ range is a combination of the resin exchange properties and the ionic nature of the solute.

When solutes do not exhibit a $\mathscr{H}$-shift, they will not focus in the column and CGC behaves like a simple continuous adsorption column. For instance, Figure 7 shows that lysozyme does not exhibit a shift in $\mathscr{K}$ in the $\mathrm{pH}$ range from 4 to 10 . Using the MS-MSFB system, we performed the countercurrent adsorption of lysozyme with commercially available nonmagnetic resin (Fig. 8). A mixed bed column of cation exchange resin (35\%) and nickel particles $(65 \%)$ was adjusted to a constant $\mathrm{pH}$ of 4 in sodium acetate buffer, and a feed solution of $0.05 \mathrm{mg} / \mathrm{mL}$ of lysozyme in sodium acetate buffer $(\mathrm{pH} 4)$ was introduced at the bottom. Because lysozyme was positively charged when introduced, and throughout the column, it was continuously adsorbed and removed from the bottom of the column. In addition, virtually no lysozyme was detected exiting from the top of the bed.

We solved the mathematical model using the experimentally determined equilibrium isotherms, a published mass transfer correlation (for packed beds) and the experimentally obtained $\mathrm{pH}$ gradient. We have found that this model with no adjustable parameters predicts fairly well the results of not only this simple adsorption run (Fig. 8) but also our solute focusing runs. The accuracy of these model predictions further indicate that the assumptions used to develop the model were indeed reasonable.
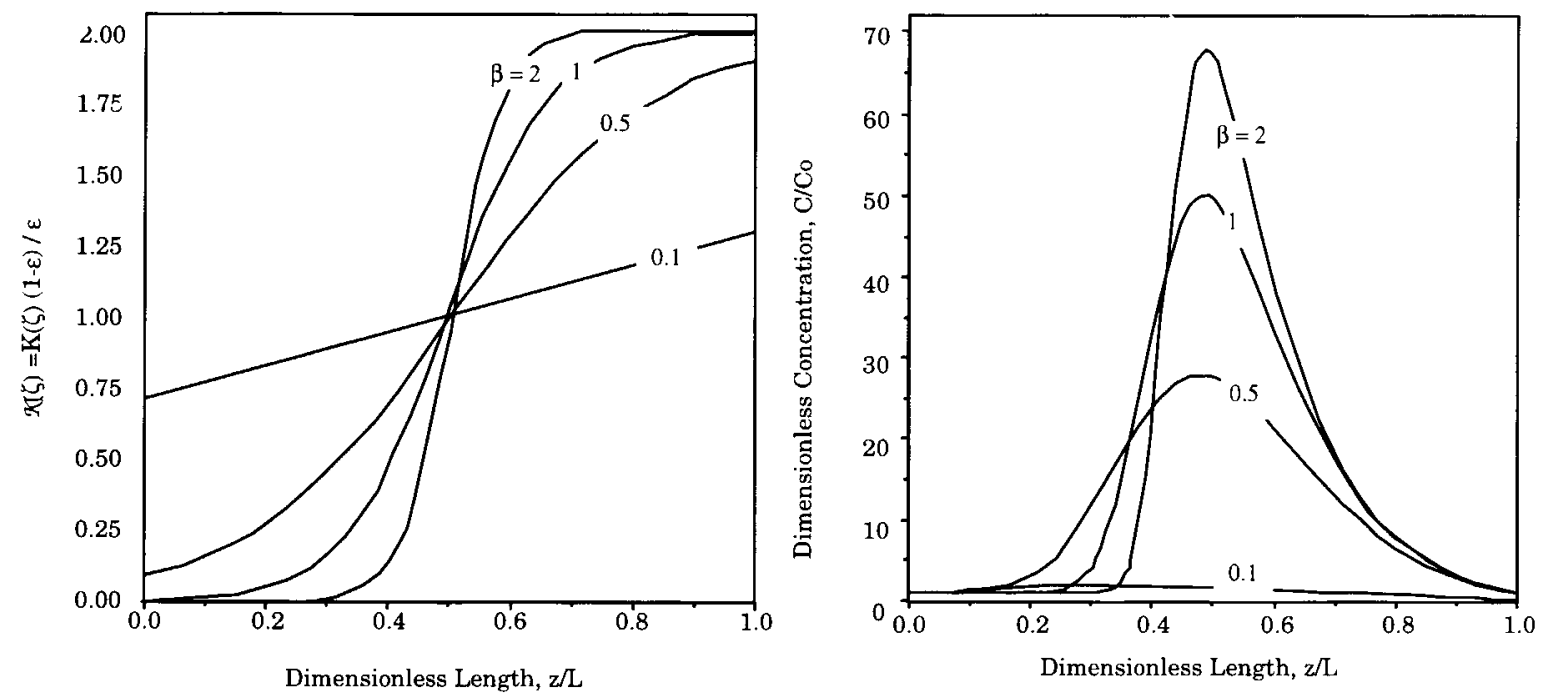

Figure 15. Effect of $\beta$ on focusing. As $\beta$ is increased, the width of the peak decreases and the achievable concentration $C / C_{o}$ increases. In this case, $S t=20, P e_{L}=105, \sigma=1$, and $\mathrm{pH}_{\mathrm{I}}=7$. 

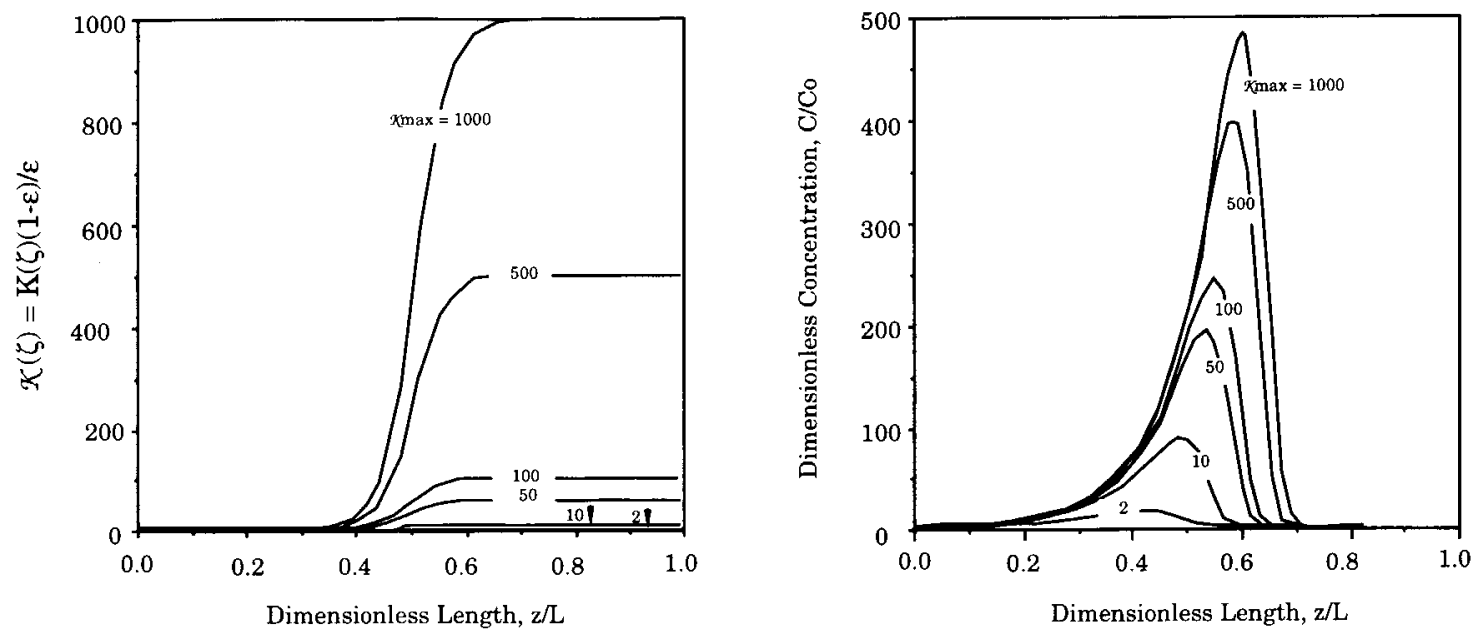

Figure 16. Effect of $\mathscr{H}_{\max }$ on peak width. As $\mathscr{K}_{\max }$ is increased, the maximum solute concentration increases. In this model prediction, $S t=10, \sigma=1$, and $P e_{L}=105$.

For solutes that exhibit a $\mathscr{K}$-shift in the column, focusing is possible. We introduced $0.2 \mathrm{mg} / \mathrm{mL}$ of myoglobin in 0.1 $M$ phosphate buffer into a stable linear $\mathrm{pH}$ gradient $\left(\mathrm{pH}_{\text {top }} 4\right.$ to $\mathrm{pH}_{\text {bottom }} 8$ ). We were able to continuously focus myoglobin at a dimensionless position of 0.5 , and were able to continuously withdraw a solution that was $0.34 \mathrm{mg} / \mathrm{mL}(1.7$ times the feed concentration) at a rate of $0.064 \mathrm{mg} / \mathrm{min}$ (see Fig. 9). Figure 9 also shows that the mathematical predictions agree quite well with the experimental results.

A more interesting focusing result was observed when we introduced a solution of $0.05 \mathrm{mg} / \mathrm{mL}$ myoglobin and 0.05 $\mathrm{mg} / \mathrm{mL}$ human serum albumin. We were able to detect a focused peak of myoglobin (1.75 times concentrated) at a dimensionless position of 0.5 and a focused peak of human serum albumin (1.2 times concentrated) at a dimensionless position of 0.75 (see Fig. 10). By withdrawing liquid streams from dimensionless positions of 0.5 and 1.0, we

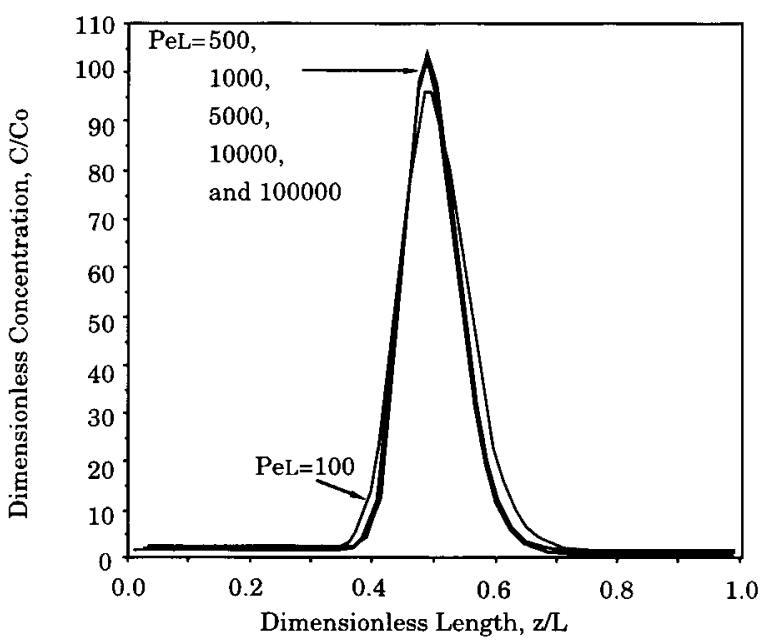

Figure 17. Effect of $P e_{L}$ on peak width. As long as $P e_{L}$ is greater than 100 , Dispersion has no effect on focusing in CGC. In this model prediction, $S t=1000$ and port withdrawal rate $=0.01 \%$ of total flow. The other model parameters values are $\sigma=1, \mathscr{K}_{\max }=20, \beta=2$, and $\mathrm{pH}_{\mathrm{I}}=7$. obtained solutions that were approximately $64 \%$ myoglobin and $70 \% \mathrm{HSA}$, respectively.

The agreement between the model predictions and the experimental results indicates that this predictive model (no adjustable parameters, all parameters determined independently) can be used to predict the optimum operating conditions of the CGC system. Thus, although the peaks shown in Figures 9 and 10 are far from optimal, we can use the model to determine that appropriate operating conditions that will yield highly concentrated and purified peaks.

\section{Optimizing Solute Focusing}

As shown earlier, there are four dimensionless parameters that affect focusing and resolution in CGC: $P e_{L}$ (dispersion), $S t$ (rate of mass transfer), $\mathscr{K}(\zeta)$ (equilibrium), and $\sigma$

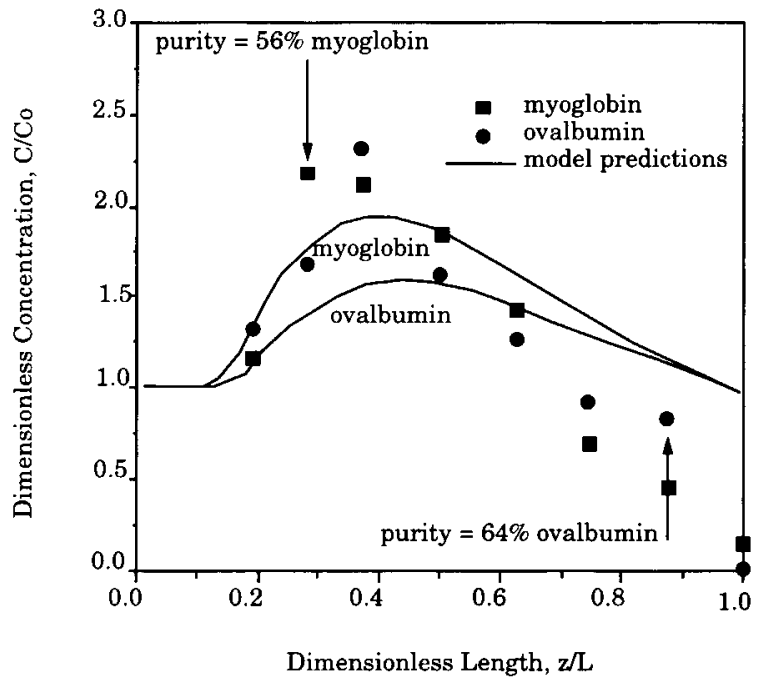

Figure 18. Separation of myoglobin and ovalbumin. In this separation, $S t=2$ which produced peaks with low concentrations. The other model parameters are $P e_{L}=105$ and $\sigma=2 ; \mathscr{K}$ is shown in Figure 7. 


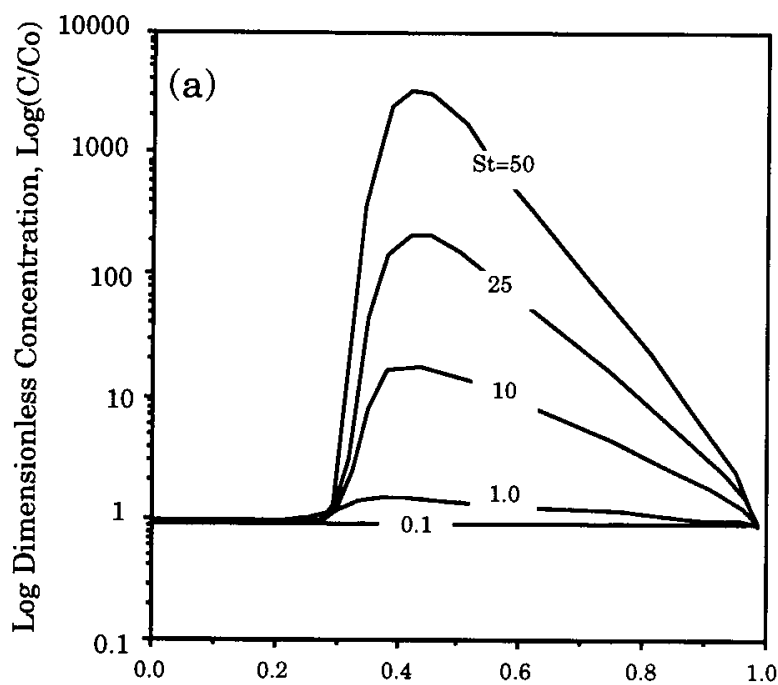

Dimensionless Length, $\mathrm{z} / \mathrm{L}$

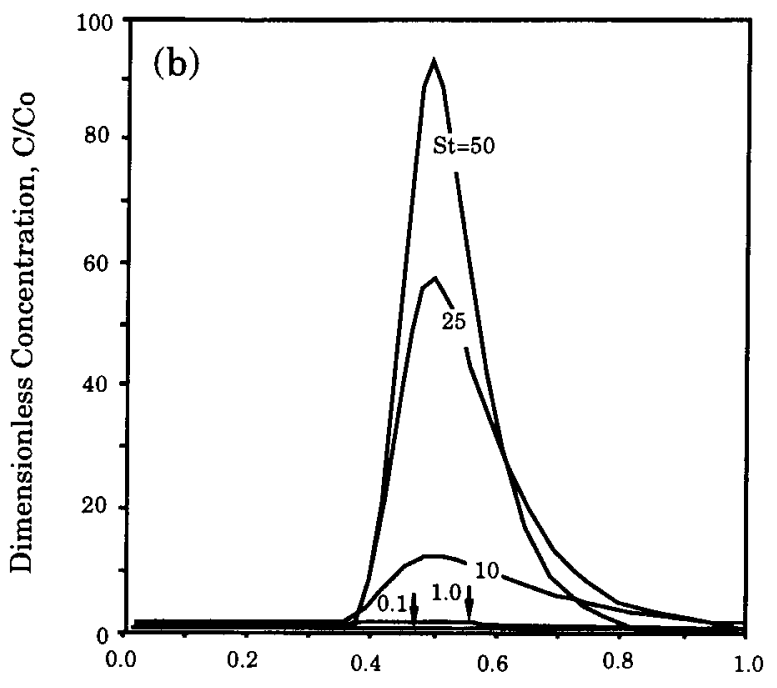

Dimensionless Length, $\mathrm{z} / \mathrm{L}$

Figure 19. Effect of $S t$ on peak width. As $S t$ in increased, the maximum value of $C / C_{o}$ increases for no port withdrawal (a) and the width of the peak decreases for port withdrawal (b). The model parameter values are $\sigma$ $=1, P e_{L}=105, \mathscr{K}_{\max }=20, \beta=2$, and $\mathrm{pH}_{1}=7$. Port withdrawal was $0.01 \%$ at $\zeta=0.5$.

(interstitial velocity ratio). We can use the mathematical model to evaluate the degree of focusing that can be obtained in CGC and to determine the effect of these parameters on peak width and peak location.

\section{Peak Location}

The focusing location of the peaks is important because it will affect the resolution of the separation. The peak maximum of a focused solute will be located near where

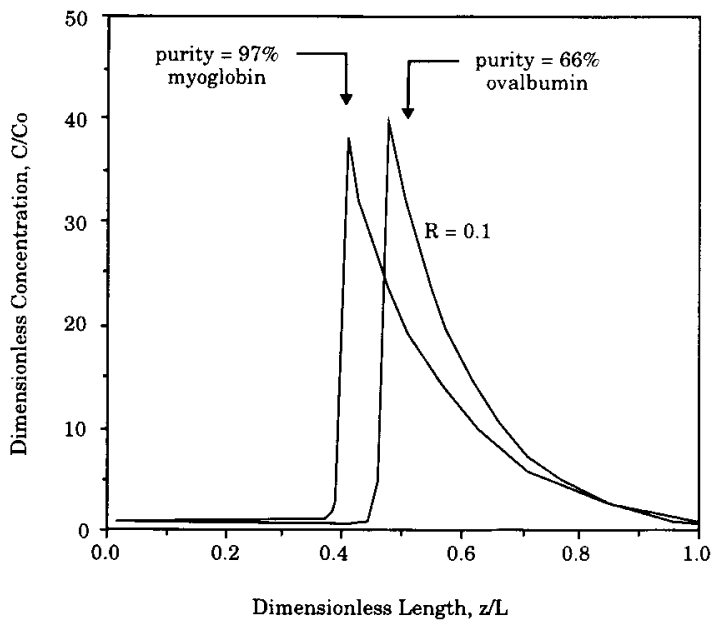

Figure 20. Effect of $S t$ on peak resolution. The model predicts that high values of $S t$ sharpen the front edge of the focused peak $(S t=100)$. Even if the peaks are not resolved, relatively pure samples can be withdrawn in this steady state system. The model parameter values are $\sigma=2, P e_{L}=$ 105 , and $\mathscr{K}_{\max }, \beta$, and $\mathrm{pH}_{\mathrm{I}}$ are determined from Figure 7.
$\mathscr{H}(\zeta)=1$. By combining an equilibrium isotherm and a typical $\mathrm{pH}$ gradient, we can generate a plot of $\mathscr{K}(\zeta)$ versus position in the column. We can then use this function for $\mathscr{K}(\zeta)$ and the mathematical model to predict the location of the peak solute concentration. As shown in Figure 11, the position in the column where each solute's $\mathscr{K}(\zeta)$ value equals 1 is the location of the focused peak.

It seems feasible that this focusing location would coincide with the location where $\mathrm{pH}=\mathrm{pI}$. However, because the local charge distribution of proteins is not uniform, ${ }^{33}$ a protein may exhibit the cyclic on/off adsorption behavior at $\mathrm{pH}$ values not equivalent to its $\mathrm{pI}$. For example, although the $\mathrm{pI}$ of ovalbumin is 4.6 , the position where $\mathscr{K}(\zeta)=1$ is $\mathrm{pH} 7.1$. For myoglobin, the position where $\mathscr{H}(\zeta)=1$ also occurs at $\mathrm{pH} 7.1$ even though its $\mathrm{pI}(\sim 7)$ is much higher than that of ovalbumin. Thus, the peak location is not necessarily determined by the isoelectric point of a solute.

By manipulating the $\mathrm{pH}$ gradient, the location where $\mathscr{K}(\zeta)=1$ and, therefore, the location of the focused peak can be changed. Figures 12 and 13 show the effect of adjusting the $\mathrm{pH}$ gradient to obtain an improved separation. In Figure 12, the $\mathscr{K}$-shifts of two different solutes are shown for a given $\mathrm{pH}$ gradient. In this case, the model predicts that

Table III. Parameter ranges.

\begin{tabular}{|c|c|c|}
\hline Parameters & Range of operation & Typical value \\
\hline$P e_{L}$ & $\begin{aligned} P e_{L} \text { significant if } & <1000, \\
\text { typical MSFB } & =10^{2} \text { to } 10^{6}\end{aligned}$ & $10^{3}$ \\
\hline $\mathscr{K}$ & $0<\mathscr{K}<1$ & $0.01-1000$ \\
\hline St & $\begin{aligned} S t & >1 \\
\text { typical MSFB } & =10^{-2} \text { to } 10^{-2}\end{aligned}$ & $5-100$ \\
\hline
\end{tabular}



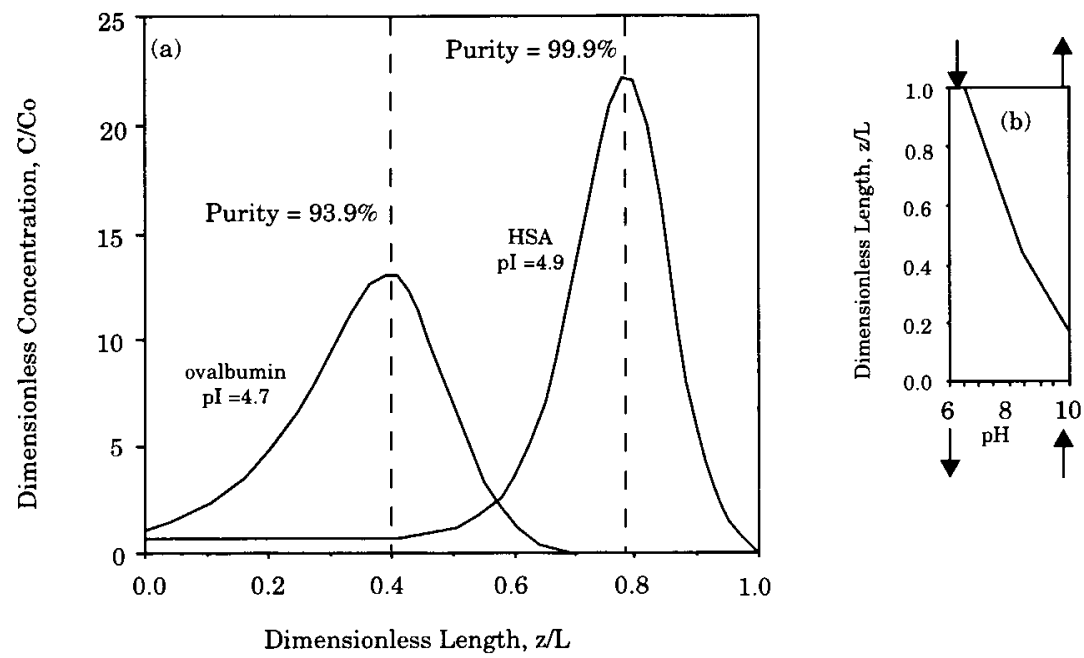

Figure 21. Prediction of multicomponent separation of model proteins. (a) The predicted separation of ovalbumin and HSA in an optimized CGC system. Experimental parameters that are achievable in the CGC system were used. The parameter values used were: $S t=50(d p=$ $100 \mathrm{~mm}, L=50 \mathrm{~cm})$ and $\sigma=1.0\left(v_{L}=v_{S}=0.027 \mathrm{~cm} / \mathrm{s}\right) . ~ \%($-shift data were used from Figure 7. (b) $\mathrm{pH}$ gradient used to calculate the hypothetical separation.

while both peaks will focus, there will be severe overlap of the peaks. When the $\mathrm{pH}$ gradient is adjusted to the more shallow profile shown in Figure 13, the peaks separate with achievable purities of $>99 \%$.

Because the shape of the $\mathrm{pH}$ gradient is manipulated by adjusting $\sigma$, the peak location is ultimately controlled by adjusting $\sigma$. A final note on peak location is that, for extreme values of $\sigma$, column end effects may result. For values of $\sigma$ near 1 , the effect on peak location is minimal; values above or below 1 cause the peak to focus at $\mathscr{K}(\zeta)$ values that are slightly above or below 1 , respectively. At high $\sigma$ values (faster liquid flow), the liquid convective rate will be greater than the mass transfer rate and solute will be carried out of the top of the column, leading to shallow, broad peaks (see Fig. 14); the upper peak in Figure 12 suffered from such an end effect. At low $\sigma$ values (faster solids flow), a similar effect is seen at the bottom of the column.

\section{Peak Width}

The $\mathscr{H}$ shift not only affects the location of the focused peak but also the width of a peak. Figure 15a shows column Kshift profiles having different $\beta$ values and the corresponding peaks that are generated in the column. Note that the larger the magnitude of $\beta$, the smaller the peak width that is obtained and the higher the maximum solute concentration. Increasing the value of $\mathscr{K}_{\max }$ can also increase the maximum solute concentration, as shown in Figure 16. However, increasing $\mathscr{K}_{\max }$ will only lead to narrower peaks when the solute is continuously removed from the column at that location using a withdrawal port; under those conditions, the maximum solute concentration is relatively constant.

An obvious parameter that affects the peak width in most chromatographic systems, but was not significant in our experimental studies, is $P e_{L} . P e_{L}$ indicates the effect of axial dispersion on the focused peak in CGC. Due to the lack of solids mixing in the MSFB, there is a low amount of radial and axial dispersion in the system as compared with normal fluidized beds. ${ }^{5}$ Our model indicates that, as long as the value of $P e_{L}$ is greater than $\sim 10^{2}$, the focusing of solutes is not affected by dispersion (Fig. 17). Based on experimental studies, typical values of $P e_{L}$ for an MSFB range between $10^{2}$ and $10^{6}$. For all experiments in this study, $P e_{L}$ $>10^{3}$.

The most important parameter that affects peak width is $S t$. St indicates the rate of transfer of a solute between the solids and liquid. High values of $S t$ (fast mass transfer) lead to high concentrations (high $C / C_{o}$ ) of the solute and sharply focused peaks. To achieve a focusing effect, $S t$ must be greater than 1.0. At a low value of $S t(1<S t<5)$ a focused peak can be obtained, but at a low concentration and with a large width. Figure 18 shows the experimental results of the separation of myoglobin and ovalbumin with $S t=2$. Note that the severe overlap of the peaks was predicted by the mathematical model.

Figure 19 shows the effect of St on the width of focused peaks. Figure 19a shows that as $S t$ is increased, and the maximum achievable concentration increases by several orders of magnitude. Note that, for Figure 19a, no liquid is withdrawn from the center of the column. Withdrawing liquid from the center of the column permits continuous collection of the focused solute, but reduces the maximum obtainable solute concentration. Figure $19 \mathrm{~b}$ shows the predictions for a column with such a withdrawal. As expected, the maximum obtainable concentration is reduced. Note that, for this case, the width of the peak also decreases.

Another important characteristic of $S t$ is that increasing the value of $S t$ will lead to a sharper front of the adsorbing 
edge of the peak. A sharp peak edge will allow at least one component to be obtained in relatively pure form even though the solute peaks are overlapping. For example, the separation of myoglobin and ovalbumin shown in Figure 18 can be improved by increasing $S t$. When $S t$ is increased to 100 (Fig. 20), the resolution is still poor, but by withdrawing myoglobin at a dimensionless position of 0.4 , a sample that is $97 \%$ pure can be obtained. Because CGC is a steady state, continuous system, and if no other peaks are withdrawn from the system, this stream can represent close to $100 \%$ recovery of the myoglobin.

\section{Model Separation}

The appropriate parameter ranges necessary for ideal focusing are listed in Table III. Typical values are also given along with values for the experimental work reported here. The low $S t$ values of our experimental runs, due mostly to the large particle diameter $(370 \mu \mathrm{m})$ of our ion-exchange resin, prevented us from obtaining sharp, highly concentrated peaks. However, using the parameter ranges listed and our mathematical model, we can predict the experimental conditions that would yield highly resolved peaks.

Particle diameters of $100 \mu \mathrm{m}$ or less should provide sufficiently fast mass transfer for proper focusing. Using a similar liquid velocity as that used in our current experiments, and a similar solids velocity, $S t$ would be $50, \sigma$ would be approximately 1 , and $P e_{L}$ would be on the order of $10^{3}$. The equilibrium data for ovalbumin ( $\left.\mathrm{pI} 4.7\right)$ and HSA (pI 4.9) were then used in conjunction with a nearly linear $\mathrm{pH}$ gradient to predict the extent of separation possible with this smaller resin. We chose these example proteins to illustrate a more complex separation because they have similar isoelectric points $(\Delta \mathrm{pI}=0.2)$. Our model predictions (Fig. 21) show that these components can be separated and focused with high resolution in the column.

\section{CONCLUSIONS}

We have developed a fully predictive mathematical model and used the model to determine the appropriate experimental conditions necessary to achieve high concentrations and high purity in CGC. We have also demonstrated experimentally that solutes can be concentrated and purified in stable $\mathrm{pH}$ gradients. A solute can be concentrated by many times its feed concentration as long as the parameters $P e_{L}, S t, \mathscr{K}$, and $\sigma$ are within the optimum ranges for that protein system. The mathematical model for focusing is in good qualitative and quantitative agreement with the experimental results and indicates that the focusing of solutes can be easily predicted. We have shown that resolution can be controlled by adjusting the key separation parameters and by withdrawing samples from optimum locations. Furthermore, we have identified the overall criteria necessary for high purity separations of amphoteric solutes in CGC.
We thank the following sources for the partial funding of this project: the National Science Foundation; the Donors of the Petroleum Research Fund (administered by the American Chemical Society); the National Consortium for Graduate Degrees for Minorities in Engineering and Science, Inc.; and the University of Michigan. We also thank A. R. Kaiser for his assistance in preparing the figures.

\section{NOMENCLATURE}

a surface area per unit volume $\left(\mathrm{cm}^{2} / \mathrm{cm}^{3}\right)$

c solute concentrations in the liquid phase per liquid volume $(\mathrm{mg} /$ $\mathrm{mL})$

d particle diameter $(\mathrm{cm})$

$D$ solute diffusion coefficient $\left(\mathrm{cm}^{2} / \mathrm{s}\right)$

$E_{L} \quad$ liquid dispersion coefficient $\left(\mathrm{cm}^{2} / \mathrm{s}\right)$

$k$ mass transfer coefficient $(\mathrm{cm} / \mathrm{s})$

$K(z)$ equilibrium constant $(\mathrm{mg} / \mathrm{mL}$ solids $/ \mathrm{mg} / \mathrm{mL}$ liquid)

$L \quad$ bed height $(\mathrm{cm})$

$\mathrm{Pe}_{L} \quad$ Peclet number (convective rate/dispersive rate)

$\mathrm{pH}_{\mathrm{J}}$ inflection point of equilibrium Kshift curve

$q$ solute concentrations in the solids phase per solid volume (mg/ $\mathrm{mL}$ )

St Stanton number (mass transfer rate/convective rate)

$t$ time (s)

$v^{\mathrm{o}} \quad$ superficial velocity $(\mathrm{cm} / \mathrm{s})$

$v_{L} \quad$ liquid superficial velocity $(\mathrm{cm} / \mathrm{s})$

$v_{S} \quad$ solids superficial velocity $(\mathrm{cm} / \mathrm{s})$

$z \quad$ position in the column $(\mathrm{cm})$

Greek letters

B scale factor

$\chi \quad$ fraction of liquid removed from the port

$\epsilon \quad$ void fraction

$\Phi$ dimensionless solid phase concentration

$\gamma \quad$ liquid velocity ratio $\left(v_{\mathrm{o}} / v_{L_{\zeta}}\right)$

$\mathscr{K}_{\max }$ maximum equilibrium value for adsorption over defined equilibrium shift

$\mathscr{K}(\zeta)$ dimensionless equilibrium parameter (mass in solids/mass in liquid)

$\sigma$ dimensionless velocity parameter (interstitial liquid velocity/ interstitial solids velocity)

dimensionless time

$v \quad$ kinematic viscosity $\left(\mathrm{cm}^{2} / \mathrm{s}\right)$

$\Psi$ dimensionless liquid phase solute concentration

$\zeta$ dimensionless length of the column

Superscripts

* equilibrium

o initial

\section{References}

1. Agosto, M., Wang, N.-H. L., Wankat, P. 1993. Amino acid separation in a multistage fluidized ion exchanger bed. Ind. Eng. Chem. Res. 32: 2058-2064.

2. Burns, M. A., Graves, D. J. 1988. Structural studies of liquidfluidized magnetically stabilized beds-a review. Chem. Eng. Comm. 67: 315-330.

3. Burns, M. A., Graves, D. J. 1985. Continuous affinity chromatography using a magnetically stabilized fluidized bed. Biotechnol. Prog. 1: 95-103.

4. Burns, M. A., Graves, D. J. 1988. Application of nagnetically stabilized fluidized beds to bioseparations. Reactive Polym. 6: 45-50.

5. Carta, G., Pigford, R. L. 1986. Periodic countercurrent operation of 
sorption processes applied to water desalination with thermally regenerable ion-exchange resins. Ind. Eng. Chem. Res. Fund. 25: 677-685.

6. Chetty, A. S., Burns, M. A. 1991. Continuous protein separations in a magnetically stabilized fluidized bed using nonmagnetic supports. Biotechnol. Bioeng. 38: 963-971.

7. Chetty, A. S., Gabis, D. H., Burns, M. A. 1991. Overcoming support limitations in magnetically stabilized fluidized bed separators. Powder Technol, 64: 165-174.

8. Ching, C. B., Ruthven, D. M. 1985. An experimental study of a simulated countercurrent adsorption system-I. Isothermal steady state operation. Chem. Eng. Sci. 40: 877-885.

9. Ching, C. B., Ruthven, D. M. 1985. Experimental study of a simulated countercurrent adsorption system-III. Sorbex operation. Chem. Eng. Sci. 40: 1411-1418.

10. Dechow, F. J. 1989. Separation and purification technology in biotechnology. Noyes Publications, Park Ridge, NJ.

11. Evans, L. L., Burns, M. A. 1995. Solute focusing techniques for bioseparations. Bio/Technology 13: 46-52.

12. Evans, L. L., Bums, M. A. 1991. The formation and use of stabilized $\mathrm{pH}$ gradients in fluidized bed separations. American Institute of Chemical Engineers Annual Meeting, Los Angeles, CA.

13. Goetz, V., Graves, D. J. 1991. Axial dispersion in a magnetically stabilized fluidized bed liquid chromatography column. Powder Technol. 64: 81-92.

14. Ivory, C. F. 1987. Continuous counteracting chromatographic electrophoresis. Paper number 1064. Presented at the Annual meeting of the AIChE, New York.

15. Lehninger A. L. 1975. Biochemistry. Worth, New York.

16. Locke, B. R., Carbonell, R. G. 1989. A theoretical and experimental study of counteracting chromatographic electrophoresis. Sep. Purif. Meth. 18: 1-64.

17. O'Farrell, P. H. 1985. Separation techniques based on the opposition of two counteracting forces to produce a dynamic equilibrium. Science 227: $1586-1589$.

18. Raj, C. B. 1994. Protein purification by counteracting chromatographic electrophoresis: Quantitative focusing limits and protein selection at the interface. J. Biochem. Biophys. Meth. 28: 161-172.
19. Ramirez, W. F. 1989. Computational methods for process simulation. Butterworth, Boston.

20. Righetti, P. G. 1983. Isoelectric focusing: Theory, methodology, and applications. Elsevier, Amsterdam.

21. Righetti, P. G., Chiari, M. 1993. Conventional isoelectric focusing and immobilized $\mathrm{pH}$ gradients: An overview (chromatographic science series). Capillary Electrophor. Technol. 64: 89-116.

22. Rosenweig, R. E. 1979. Fluidization: Hydrodynamic stabilization with a magnetic field. Science 204: 57-60.

23. Ruthven, D. M. 1984. Principles of adsorption and adsorption processes. Wiley, New York.

24. Ruthven, D. M., Ching, C. B. 1989. Counter-current and simulated counter-current adsorption separation processes. Chem. Eng. Sci. 44: 1011-1038.

25. Schweitzer, P. A. 1988. Handbook of separation techniques for chemical engineering. 2nd edition. McGraw-Hill, New York.

26. Sinha, P., Galacteros, F., Righetti, P. G., Kohlmeier, M., Koettgen, E. 1993. Analysis of hemoglobin variants using immobilized $\mathrm{pH}$ gradients. Eur. J. Clin. Chem. Clin. Biochem. 31: 91-96.

27. Sluyterman, L. A. E., Elgersma, O. 1978. Chromatofocusing: Isoelectric focusing on ion exchange columns. I. General principles. J. Chromatogr. 150: 17-30.

28. Sluyterman, L. A. E., Wijdenes, J. 1978. Chromatofocusing: Isoelectric focusing on ion exchange columns. II. Experimental verification. J. Chromatogr. 150: $31-44$.

29. Sluyterman, L. A. E., Wijdenes, J. 1981. Chromatofocusing. III. The properties of a DEAE agarose anion exchanger and its suitability for protein separations. J. Chromatogr. 206: 429-440.

30. Terranova, B., Burns, M. A. 1989. Continuous cell debris filtration using a magnetically stabilized fluidized bed. Biotechnol. Progr. 5: 98-104.

31. Terranova, B., Burns, M. A. 1991. Continuous cell suspension processing using magnetically stabilized fluidized beds. Biotechnol. Bioeng. 37; 110-120.

32. Tyn, T. T., Gusek, T. W. 1990. Prediction of diffusion coefficients of proteins. Biotechnol. Bioeng. 35: 327-338.

33. Wheelwright, S. W. 1991. Protein purification. Hanser, Munich. 